\title{
Fendas em família: violência e lirismo na prosa de Vilma Arêas
}

\author{
Paola Fernandes Zamboni ${ }^{1}$
}

No prefácio à coletânea $O$ Conto Brasileiro Contemporâneo ${ }^{1}$, Alfredo Bosi desenvolve a idéia de que haveria, nos desdobramentos recentes do gênero, uma oscilação entre duas vertentes: uma realista documental e outra experimental e intimista. Após apresentar exemplos retirados da obra de grandes contistas das décadas de 60 e 70, o ensaio argumenta que, provavelmente, essa oscilação ainda iria perdurar por muito tempo. O conto brasileiro estaria diante da alternativa entre um relato fosco da brutalidade corrente ou uma sondagem mitica do mundo, da consciência ou da pura palavra².

A prosa de Vilma Arêas parece colocar em questão os limites dessa divisão abrupta, pois em seus contos as duas alternativas, em vez de excludentes, se mesclam na própria realização formal do texto. A violência da realidade brasileira contemporânea, estudada desde sua célula máter, a família e suas relações, é narrada de tal modo que escapa à mera objetivação da violência, adquirindo assim um lirismo próprio, baseado em uma sondagem dos potenciais expressivos da linguagem, que leva a forma a incorporar procedimentos do poema em prosa e da montagem modernista.

Desde Partidas, seu livro de estréia lançado em 1976, a estrutura fundamental do conto é levada ao limite, justamente por se inventar no cotidiano, como aponta Luiz Costa Lima, em vez de ser usada como uma partida ganha, cujos lucros se investem na literatura. $\mathrm{O}$ livro contém 26 pequenas obras nomeadas pelas letras do alfabeto, cada uma a letra inicial da palavra que dá nome ao conto mais um subtítulo. Os temas são retirados do dia a dia, abrindo com o orçamento de um mestre-de-obras do século XIX até conversas entre namorados, pequenas biografias ou anedotas. Em peças curtas, mas de densidade impressionante, a trama surge com estrutura de poema em prosa, uma construção em frases curtas, como notas musicais que martelam os percalços da vida até o derradeiro momento da narrativa. Cabe lembrar Julio Cortázar:

\footnotetext{
o sempre assombroso dos contos contra o relógio está no fato de potencializarem vertiginosamente um mínimo de elementos, provando que certas situações ou terrenos narrativos privilegiados podem ser traduzidos numa narrativa de projeções tão vastas como a mais elaborada das nouvelles ${ }^{3}$.
}

Nos contos de Vilma Arêas, o leitor se encontra num terreno onde o assombro de Cortázar é distendido ao seu ponto máximo.

O volume $A$ terceira perna foi publicado em 1992, doze anos depois de Partidas. Se a autora já surgia formalmente madura, neste livro suas qualidades são reconhecidas pela crítica, que a agracia pela segunda vez com o Prêmio Jabuti. São vinte e quatro contos agrupados em três blocos que, como diz a orelha de Clara Alvim, se propõem a narrar o inenarrável. Mais uma vez Vilma Arêas implode as definições tradicionais do gênero, fugindo da narrativa dramática e unívoca, que gravita em um só conflito e unidade de 
ação, e optando por uma construção aberta, que se aproxima novamente da cadência musical do poema em prosa. Os temas vão desde notícias de jornal, recortes da vida cotidiana, digressões acadêmicas e homenagens a Truffaut e Nise da Silveira, até uma certa amargura cívica; são narrativas retiradas da memória e do esforço para o esquecimento, que exigem do leitor um esforço para descortinar o mundo que elas escondem.

No conto "De cacos e buracos" encontramos uma narrativa cronológica, ainda que esparsa, composta por frases soltas que tecem em linhas gerais um panorama da vida amorosa da personagem, uma mulher com um casamento infeliz e um amante insatisfatório. A escassez de elementos é patente, as descrições são mínimas, as caracterizações somente as necessárias, mas a tensão se acumula da primeira à última sentença, e suas projeções se propagam para além do narrado, de maneira desconcertante. Num primeiro momento, temos um vislumbre da menina sonhadora, da educação severa que recebeu e das frias impressões gravadas. Na seqüência, podemos adivinhar um relacionamento, junto com o casamento já consumado com outro, a vida prosaica e cotidiana machucando. Então, o casamento se desfaz, e a nova existência se mostra ainda mais dura que a anterior, o novo parceiro ainda mais frio.

As personagens do conto são todas anônimas, não sabemos o nome da moça de olhos verdes, nem de seu marido baixinho ou de seu amante ciumento. Eles aparecem na narrativa como as características que representam. Mas a parca descrição não a transforma em tipo, pois a tessitura lírica da narrativa constituída de frases soltas e elipses particulariza o indivíduo que aparece no conto. A personagem, construída pelas lembranças narradas através de imagens, deixa brechas a serem preenchidas pelo leitor, não apenas a partir do que é dado, mas levando em conta suas próprias experiências, característica sempre presente nos textos de Vilma Arêas.

As referências biográficas estão sempre presentes, tanto aqui quanto no livro Aos trancos e relâmpagos, Prêmio Jabuti em 1988, que relata um caso passado na infância, quando a autora se apaixonou por um tio muito brincalhão, que também morava no lar severo onde cresceu. Enciumada quando o tio arranja uma namorada da idade dele, ela tentou separar os dois, mesmo sem entender muito bem o porquê. A menina de Aos trancos e relâmpagos traz facetas que mais tarde vão despontar em outras personagens na obra de Vilma Arêas, assim como em Partidas vemos elementos que serão retomados continuamente. Aqui já aparece uma certa dificuldade em compreender o amor, o foco na família como célula menor da sociedade, e a violência social por ela refletida.

"Estudo a ponta seca", do livro $A$ terceira perna, trata de um episódio de violência sexual praticada pelo narrador com a conivência e participação não ativa de seu irmão, que também se interessa pela moça. Logo no início, ele nos informa das confidências do irmão e de como ficava medindo os gestos da moça, a quem se refere como "bichinha", com evidente desprezo. Na seqüência, relata como correu atrás dela e a agarrou à força, como gentilmente afastou a cachorrinha Naná e as estratégias que usou para amolecer a vontade da moça e finalmente possuí-la. Durante a narrativa, ficamos sabendo da presença do irmão na cena e de parte das confidências que fez. O conto termina com o final do próprio ato, a moça se vai e chega o bonito irmão, a quem o narrador garante que só enfiou a cabecinha. 
São quatro personagens: o narrador, seu irmão H, a bichinha e Naná. Naná, a cachorrinha, é a única que carrega um nome próprio, e também a única a se opor ao ato praticado contra a moça. Não é tão pormenorizadamente humanizada quanto a Baleia de Graciliano Ramos, mas podemos traçar um paralelo com essa outra notória cachorrinha por trazer um nome próprio, o que, como nos lembra Ian Watt ${ }^{4}$, constitui um elemento fundamental, na narrativa moderna, para a caracterização de personagens mais realistas. No caso do nosso conto, o nome próprio de Naná, em oposição aos outros personagens, todos alcunhados, denota a clara intenção de torná-la mais humana, o que é crucial para a história. Os sentimentos de Naná não só transparecem nas palavras do narrador, quando esse afirma que sempre foi o seu favorito, como também na distração que oferece saltando em volta do casal e esfregando o focinho de veludo nas pernas dele, um contraponto moral ao ato violento que se segue.

Ao contrário da cachorrinha, a moça é retratada como um bicho, e desde o início nos é apresentada como bichinha, o que transborda para a descrição de seus atos:

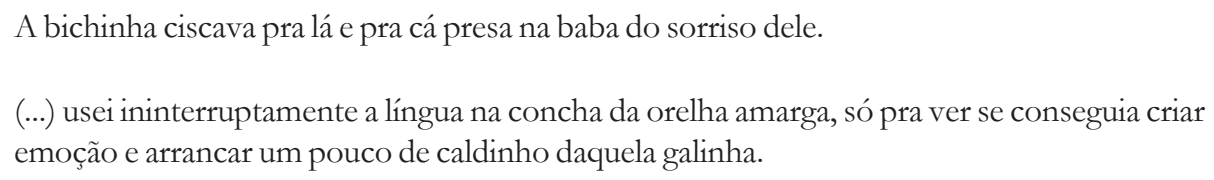

A desumanização fica ainda mais evidente quando ela, agarrada pelo narrador, não emite um som sequer. E muda permanece até o final da função, quando desaparece como por encanto junto com a pecinha arrancada a custo com uma mão só. Nada sabemos dos seus sentimentos, do que pensou ou deixou de pensar, ou sequer se pensava. A bichinha, na verdade, não passa de um objeto no conto, e como tal é retratada. O desprezo do narrador por ela é evidente não só na maneira como a trata, mas também nos comentários da narrativa:

(...) e não pude deixar de supor que ficaria manchada como se tivesse um tipo qualquer de lepra.

Era impressionante. Seca como um areal.

Só descobrimos as facetas do narrador a partir de sua relação com as outras personagens: sabemos que é o favorito de Naná, que seu irmão é o mais bonito, e que com muito custo conseguiu seduzir a bichinha. O próprio prazer que sente ao consumar o ato com a moça só se realiza através do irmão, seja pela presença deste na cena, seja pelo desejo que $\mathrm{H}$ nutre por ela. Para o narrador é mais prazeroso encostar a testa no rosto do irmão no final do ato do que o próprio ato em si.

A abordagem polifônica do conto nos leva aqui a uma leitura diferente do tema presente na história. Uma leitura dialógica nos faz crer que se trata do simples relato de um estupro, mas se olharmos o conto como um todo, sob a ótica da polifonia bakhtiniana, podemos perceber que as muitas vozes que se sobrepõem na trama (narrador, o irmão, Naná, o silêncio da bichinha) escondem uma verdade mais profunda, trazida à tona pelo conjunto como num acorde musical, aproximando novamente a narrativa da concepção 
precisa e expressiva dos poemas em prosa. Então o verdadeiro tema se desvela, e percebemos que toda a ação não passa de uma grossa moldura para o que realmente interessa: a relação entre os dois irmãos, o amor incondicional que o narrador sente por $\mathrm{H}$ e o medo que tem de ser arrancado fora da vida deste (e aqui se misturam o sentido figurado e o literal, com evidentes ecos sexuais). Esse medo, a mola que move as ações que seguem as confidências de $\mathrm{H}$, só é explicitado no final, quando ele pergunta para a bichinha

se ela fazia só porque ele disse, mas evidentemente não consentiria, sempre tive medo que me arrancassem fora.

A ausência de um ponto entre os períodos demonstra o turbilhão em que se encontram os pensamentos do narrador e denota o medo que sente, só apreendido completamente pela análise das vozes soantes e dissonantes presentes no texto.

Narrador e $\mathrm{H}$ parecem concordar em tomar a bichinha à força. $\mathrm{H}$ porém sente algum desejo por ela, enquanto o narrador, por suas próprias ações e colocações, parece só sentir desprezo. A moça, de quem deveríamos esperar mais resistência ao estupro, é tão destituída de suas qualidades humanas que sequer tem uma voz própria, seu lugar humilde, de peça de trabalho que varre o lixo do meio da sala, não a permite reclamar, fica a cargo da cachorrinha zelar pelo seu bem. Essa multiplicidade de vozes tomadas no conjunto nos mostra um narrador fragilizado e assustado, que toma à força o brinquedo do irmão por ciúmes e se deleita com a rua brilhante da última frase do conto, um claro contraponto à sombra que o cabelo liso do irmão faz no seu rosto, logo no primeiro enunciado da história.

H cheirava feito cavalinho novo e a rua inteira brilhava, como se estivesse molhada.

A análise do tempo na narrativa também nos revela seu caráter polifônico, o conto abre com um relato em primeira pessoa de um fato já decorrido:

Ele me contava tudo com todas as minúcias e seu cabelo liso fazia sombra no meu rosto. A bichinha ciscava pra lá e pra cá presa na baba do sorriso dele. Eu tinha certeza que tudo não passava de fantasia, (...)

e continua discorrendo sobre os fatos que se sucederam como num sumário narrativo, e só quando o narrador se decide a pegar a bichinha é que nos damos conta de que se trata de um retrospecto. Ele parte para a ação e há uma aproximação da narrativa, somos como que jogados para dentro da cena e passamos a acompanhá-la bem de perto até o surgimento de Naná. Com a intromissão da cachorrinha, somos novamente afastados por uma interpolação, que nos remete a algum passado, informando que ele sempre foi o preferido dela, e então voltamos para a cena, que passa a descrever a ação das outras personagens. A partir dá, a narrativa segue interpolada por pensamentos e lembranças do narrador, que a jogam ora para o tempo presente, onde ocorre o estupro, ora para um passado recente como o que abre o conto, ora para um futuro incerto, onde reina a suspeita de gravidez. 
Esse caráter multifacetado do tempo na narrativa é característico de outras grandes contistas modernas, como Clarice Lispector e Virginia Woolf, em cujas obras os fatos ou ações externas tocam o narrador em algum ponto sensível, desencadeando toda uma cadeia de pensamento e memórias pertencentes a uma outra realidade. Mas em Vilma Arêas não acompanhamos a cadeia de pensamentos que se desenrola do detalhe, e sim pequenas frases pertencentes a um ou outro tempo, interpoladas na narrativa, e que funcionam como temas musicais, só completamente apreendidos se julgados dentro do todo, revelando ao leitor um outro ângulo da história. É o tratamento polifônico da imagem de que nos fala Auerbach, num importante capítulo do livro que, não por acaso, trata justamente da representação literária da realidade. A atenção tende a se concentrar na representação exterior do tempo e da realidade, no caso o estupro, enquanto o que realmente importa são as coisas que não vemos diretamente, mas sim pelo reflexo que elas produzem: a relação do narrador com seu irmão.

Nas suas considerações sobre o conto brasileiro, Bosi coloca a vertente existencialista de Clarice Lispector, assim como a narrativa de Virginia Woolf baseada na memória, no campo oposto ao da representação da brutalidade cotidiana ${ }^{6}$, cujo exemplo mais gritante seria encontrado nas narrativas de Dalton Trevisan. Como vemos, Vilma Arêas rompe com a divisão estanque entre esses dois âmbitos, já que em seus contos encontramos a violência da narrativa seca de Trevisan e, ao mesmo tempo, a constante perplexidade diante da vida e das coisas, tão presente em Clarice. A narrativa enxuta de Vilma, para dar conta da violência real, não exclui o relato intimista, nem cancela, em busca de uma suposta objetividade isenta, a perplexidade do narrador e, junto com a dele, a do leitor que se dispõe a entrar no jogo.

No conto que analisamos, além do tempo, também o espaço se dilata. Nada é bem delimitado, sabemos que há um dentro e há um fora, um terreno e uma casa, mas a ambientação é fraca. Conhecemos detalhes como os pedregulhos e as folhas secas que rangiam sob as patas de Naná ou o traçado dos galhos apertando a chita do vestido, mas nunca podemos dizer com certeza onde se encontram as personagens. Essa parca caracterização serve a um propósito, aproximar ainda mais os dois irmãos, ao tornar indistinto o limite entre as coisas. Não importa mais o que é dentro ou o que é fora, as membranas físicas que separam o mundo tornam-se porosas à medida que a consciência dos dois irmãos se mistura no ato:

Pela janela iluminada vinha o risinho dele. Entrecortado e rouco, perfeitamente audível apesar de nossa respiração angustiada. Como se a parede fosse uma parede de vento.

No final da narrativa, entretanto, o espaço físico volta a se cristalizar. $\mathrm{H}$ vem da esquina quando a moça desaparece no final da função e surge a rua brilhante como se estivesse molhada, um lindo contraponto com a sombra no rosto que vimos no início do conto.

"Estudo a ponta seca" é uma pequena obra-prima do conto contemporâneo. Nele, cada elemento apresenta sua função específica, nada aparece ao acaso, e cada frase remete a uma aglomerado de sensações e idéias, todas servindo a algum propósito. Intensidade e tensão se sobrepõem na trama, provocando essa explosão de que nos fala Cortazar, 
quando compara o conto breve à fotografia, que abre de par em par uma realidade muito mais ampla

[existe] uma necessidade de escolher e limitar uma imagem ou acontecimento que sejam significativos, que não só valham por si mesmos, mas também sejam capazes de atuar no espectador ou no leitor como uma espécie de abertura, de fermento que projete a inteligência em direção a algo que vai muito além do argumento visual ou literário contido na foto ou no conto ${ }^{8}$.

O recorte é claro, uma cena de extrema violência, mas ainda assim, o tratamento dado a ela é lírico, acetinado, algo entre o traço duro de J. Borges (artista brasileiro, cujas gravuras de cordel foram analisadas pela autora) e a serenidade e riqueza de detalhes realistas de Albrecht Dürer. Vilma Arêas realiza com maestria seu estudo multifacetado, e nos apresenta uma maravilhosa ponta-seca, sutilmente elaborada na sua narrativa.

Trouxa Frouxa, livro publicado em 2000, traz na orelha um comentário de Francisco de Oliveira, afirmando que a maturidade da escrita de Vilma Arêas realiza um programa em que matéria e forma se fundem até se tornarem indistinguiveis. O livro é composto por trinta e três peças. A variedade temática e formal é grande, passando por relatos da ditadura, como em "Algaravia" ou "Acervo", descrições de cenas e paisagens como alguns dos intitulados "Cromo" e "Praia", pequenos epigramas ou poemas em "Rol (Inventário anacrônico)", impressões e cenas catadas da infância como em "Nós", que segundo o comentário da autora durante a entrevista feita em 2004, parece os nós da trouxa, mas é o pronome, jogando a narrativa para a esfera das experiências pessoais. A estrutura é fragmentária, compondo uma escrita caleidoscópica como coloca Yudith Rosenbaum, na qual o todo é sempre faltante, lacunar, como os mistérios indissolúveis ${ }^{9}$. Vilma diria elíptica. De qualquer forma, a participação do leitor se faz necessária para unir as pontas e construir o sentido.

Neste livro, Vilma Arêas mostra-se ainda mais sucinta, experimentando com uma prosa quase crua, mas carregada de um lirismo arrebatador. Os contos são curtos, às vezes apenas uma linha, como em "Dudu" - Assim como en gosto da minha cachaça ela gosta de sofrer - uma frase solta, algo catado do mundo que se configura como um poema em prosa, o que a aproxima tanto do projeto literário do poeta Francisco Alvim como da narrativa curta e pungente de Dalton Trevisan, muito admirado pela autora, por sua capacidade de síntese e pela arte da elipse, onde se escreve pouco para que o leitor pense muito. As frases catadas de Vilma Arêas vêm embebidas da sabedoria popular, dos preconceitos e da coloquialidade das ruas, deixando respirar pela tessitura do conto o viés da violência, tanto no âmbito da família, quanto no âmbito social. Sem ser ideológica ou engajada, a narrativa pode vir carregada de sentido político (como nos lembra Adorno), ao mostrar nua e crua a realidade machista do país; ou crítica social, quando trata a violência como algo tão corriqueiro como um gole de cachaça.

No pequeno conto "De cacos e buracos" encontramos um ambiente opressivo, e podemos sentir o peso da sombra sempre presente do Pater Familias, figura recorrente na prosa da autora e que surge com poder de vida e morte, figura cunhada no seio da escravidão, que ainda embebe todas as relações da sociedade brasileira, e que configura uma antítese brutal entre as pessoas e os outros, as coisas, os objetos, as peças de trabalho. Em entrevista, Vilma comentou o quão diferentes são as relações familiares de países 
que não tiveram escravidão e países com sistema escravista, essa maneira de olhar o mundo e dividir as pessoas de alguma forma é passada dentro de casa, daí o poder absoluto do Pater Famílias e toda a violência que perpassa essas relações.

O conto "Ele" traz justamente a figura desse Pater Familias, apesar de não ser assim denominado no texto. Depravado, com um viés pedófilo e um insaciável apetite por mulheres cada vez mais jovens, ele gostava de cabacinhos e não perdia a oportunidade de anunciar a qualquer hora do dia a chegada de um galheto novo, nome dado às meninas virgens no bordel mais famoso da cidade. A figura é degradante, sua caracterização no decorrer do conto não nos poupa os detalhes grotescos e as colocações racistas que faz. Essa personagem pode ter, por tradição, poder equivalente ao absoluto, mas o uso que faz dele é repulsivo e mesquinho, quando atormenta o filho moreno ou abusa das meninas novinhas. O foco é a família, mas a violência presente na sociedade se espelha nela, seja através do racismo, seja através do poder exercido pelo Pater Famílias, em cujo manda e desmanda relembramos o coronelismo, fruto da tradição patriarcal brasileira na formação da família e da sociedade.

Em "Ele" também encontramos na irmã horrorizada, a mulher sensível que povoa as narrativas de Trouxa frouxa, permeável às injustiças sociais e aos revezes da vida, é ela que dá a tônica do conto, intimista e cheio de perplexidade, com o comentário pontual aos excessos do outro: -Mas o que é isso. Como é que pode. Uma criança morta de fome.

O espaço reservado às mulheres na família é aquele de um enfeite, a própria irmã horrorizada se destaca do corpo do texto flutuando sozinha num parágrafo só seu, seguida do comentário, mas não ligada a ele pelo sinal gráfico de dois-pontos. Na narrativa, no entanto, essas vozes femininas até mesmo no silêncio se rebelam contra o papel que lhes é conferido, e se levantam, jogando uma luz clara e forte na crueldade e na violência dessas relações. A moça de olhos verdes de "De cacos e buracos" escande as palavras para evitar o colapso, enquanto a bichinha de "Estudo a ponta seca" não emite um ruído sequer ao ser abusada. A irmã horrorizada ousa um comentário, mas sequer sabemos se o dirigia ao Pater Familias. A própria linguagem (ou a ausência dela) e sua organização semântica se encarregam de transpor essa percepção da violência dentro dos contos, e possibilitar a sua compreensão pelo leitor atento.

O cúmulo da violência se dá quando o pai de família exemplar acaba comendo por engano a própria filha de nove anos, que morava longe com a mãe, num desfecho grotesco com ares de canibalismo:

Na verdade não comeu bem. Estava velho demais, faltavam-lhe dentes e a carne da menina era excessivamente dura.

evidenciando a caracterização desumanizada dos homens que habitam algumas narrativas da autora. O conto se apresenta como relato baseado na memória, apesar das falas que despontam aqui e ali na estrutura, o narrador em primeira pessoa torna-o pessoal. $\mathrm{O}$ arco de tensão descrito se aproxima da impressão total proposta por Poe ao afirmar que Em toda a composição não deve haver nenhuma palavra escrita cuja tendência, direta ou indireta, não esteja a serviço desse desígnio preestabelecido ${ }^{10}$. Sua estrutura, no entanto, não é fechada, sendo também este caráter poroso o que o aproxima do poema em prosa. 
Atenção e comprometimento são fundamentais para a apreciação da narrativa, uma vez que a descrição da violência está subjetivamente expressa na própria linguagem, na organização do texto e na caracterização das personagens a partir de experiências diretas internas ou externas, sempre seguindo uma configuração esquemática que exige do leitor o papel de preenchê-las com suas próprias experiências. É o que podemos ver espelhado ao longo dos contos, seja no desespero que brota dos olhos da moça de "De cacos e buracos", seja na relação de total dependência entre os irmãos de "Estudo a ponta seca", seja na impotência dos filhos diante do pai todo poderoso de "Ele".

Se toda ficção passa por certos focos pessoais, como afirma Vilma, a dela não é exceção. O que a faz extraordinária é a capacidade e a sensibilidade de filtrar as experiências pessoais e familiares e espelhá-las na sociedade, montando assim um panorama da família brasileira com toda a violência que lhe é inerente. A violência é clara, mas o lirismo que se configura em contraponto transparece na construção semântica do texto, que metaforiza esta violência na própria linguagem. A violência da realidade brasileira contemporânea pode ser vista e percebida pelo leitor atento como um relato fosco da brutalidade corrente, mas não surge no texto como palavra de ordem na crítica social. Aqui pensamos como Adorno, o engajamento é inerente à forma e a crítica social transparece na tessitura da trama e nos relatos, pessoais ou fictícios, que constroem a obra gerando um lirismo próprio, próximo do que Bosi chama de sondagem mitica do mundo, da consciência e da palavra, mas que caminha para um relato literário original da realidade brasileira. Vilma Arêas mescla as duas faces do mesmo rosto da máscara estética possível que Bosi propõe para a literatura dos nossos dias, realizando no seu projeto o quase impossivel: mergulhando de corpo inteiro no pensamento e na ação. Em seus estudos a ponta seca, pequenas obra primas da literatura contemporânea, a crítica social se encontra tão intrinsecamente ligada à forma lírica em que o problema se coloca que é impossível dissociá-la da trama. A brutalidade da violência nua e crua se engasta no improvável lirismo da narrativa.

Notas

1 Este ensaio é um resumo do relatório da pesquisa de iniciação científica desenvolvida entre 2004 e 2006, com apoio da FAPESP, junto ao Departamento de Teoria Literária e Literatura Comparada (FFLCH-USP), sob orientação do Prof. Jorge de Almeida.

2 BOSI, Alfredo (org.). O Conto Brasileiro Contemporâneo. São Paulo: Cultrix Editora da Universidade de São Paulo, 1975, p.7-22

3 Idem, p.22

4 CORTÁZAR, Julio. "Do Conto Breve e Seus Arredores” in Valise de Cronópio. São Paulo: Editora Perspectiva, 1974 , p. 229.

5 WATT, Ian. A Ascensão do Romance. São Paulo: Companhia das Letras, 1990.

6 AUERBACH, Erich. “A meia marrom” in Mimesis. São Paulo: Perspectiva, 1971.

7 BOSI, Alfredo (org.). Op. cit.

8 CORTÁZAR, Julio. "Alguns Aspectos do Conto” in Valise de Cronópio. São Paulo: Perspectiva, 1974, p. 151. 9 Ibidem.

10 ROSENBAUM, Yudith em resenha publicada na revista Fições nº 6. Rio de Janeiro: 7 Letras, 2000, pp. 127132.

11 POE, Edgar Allan citado de GOT'TLIB, Nadia. Teoria do Conto. São Paulo: Ática, 1985, p. 35. 